I 902 ), Author's Edition, 54 pp. -The paper makes a strong presentation of evidence showing the powerful influence of carbon and carbon compounds in the formation of metallic and sulphide ore deposits, especially where these are found in limestones or dolomites impreguated with carbonaceous matter, or in sandstones or other formations associated with coal or hydrocarbons. In certain fields (as the lead and zinc regions of Southwestern Missouri) the author's investigations have shown "that the solid oxygenated hydrocarbons, particularly when in fine powder and in suspension in the water circulating through the ore bodies, are the most energetic and powerful reducing agents known." Hence it is fair to conclude that they may have exerted similar effects elsewhere where their presence is manifest in the ore-carrying strata. Even the gaseous liydrocarbons were probably very active under the conditions accompanying and following their formation from bitumens and coals during igneous intrusion. Theoretical equations are given for the reduction of oxidized metallic salts by a variety of natural carbonaceous bodies. There is also a table showing the relative reducing power of several of these and of a large number of native minerals, based on a scale of Hydrogen $=$ I oo as the most effective of all, from which it appears that all forms of carbonaceous matter far exceed in theoretical reducing power any one of the minerals. The relative order of the principal deoxidizing agents is : I, bitumen ; 2, bituminous coal and carbonaceous shale; 3 . marcasite and pyrite; 4, blende; 5, galena. Ferrous sulphate stands next to the bottom of the list notwithstanding its known great influence in effecting both reduction and oxidation. "This low quantitative value is in many instances more than offset by the large amount of ferrous sulphate continuously supplied by the progressive oxidation of the pyrite in the ore deposits."

W. F. Hili,EBRAND.

\title{
ANALYTICAL CHEMISTRY.
}

Analysis of Crude Sulphur. By Frank B. CARPENTER, J. Soc. Chem. Ind., 21, 832.-In some crude Mexican sulphur only a part of the sulphur was soluble in carbon bisulphide and the ignition method could not be used on account of the presence of calcium sulphate containing water of crystallization. As this water was gradually given off at $100^{\circ} \mathrm{C}$. the moisture was determined by drying in a vacuum over sulphuric acid. The substance was then boiled with dilute hydrochloric acid, filtered in a Gooch crucible, dried and weighed. This removed the calcium sulphate; the sulphur in the residue was found to be readily soluble in carbon bisulphide.

B. S. CUSHMAN.

On Screens Transparent Only to Ultra-Violet Light and Their Use in Spectrum Photography. By R. W. WOOD. Phil. 
Mag. and J. Sci. (6), 5, 257-263. - The author has made a screen quite transparent to the ultra-violet rays and yet opaque to visible light. Very dense cobalt glass, coated with a thin film of gelatin stained with nitroso-dimethyl-aniline, is transparent only to the extreme red and to the ultra-violet, and the red is removed by a thin sheet of Chance's " signal-green" glass. This screen freely transmits everything between wave lengths 34 and 38. The employment of glass screens limits the ultra-violet transmission, and a screen of this description is useful chiefly for lecture demonstrations. A combination of a tube furnished with quartz ends, on one of which is a thin film stained with the nitroso compound, transmits all of the ultra-violet, and only the extreme red, but it is very inconvenient to use. A screen, useful perhaps in astrophysical work, is made by combining nitrosodimethyl-aniline with a small amount of the dye uranine, the latter removing the bluish greet portion of the spectrum which affects the photographic plate. These screens make it possible to photograph the ultra-violet lines in grating spectra of higher orders than the first, entirely uncontaminated by the risible radiations which overlie them. Other applications are suggested. The author gives a number of photographs of the spectrum of the cadmium spark taken with varying exposures and with layers of the various solutions and glasses with which he rorked before the slit of the spectrograph; also some of the iron and cadmium spark spectra which show very clearly the utility of the nitroso screen in photography with the concave grating. Two photographs of the same landscape, one taken on an orthochromatic plate by yellow light through a screen of dense aurantia, the other taken on an ordinary plate by ultra-violet light, show distinctly the absence of contrast in the latter except between white objects and objects not white.

BENTON DALES.

A Sensitive-strip Spectropolariscope. BY D. B. BRACE. Phil. Mag. and J. Sci., (6), 5, I6I-17o. - The author uses, instead of the ordinary nicols, cylinders of $\alpha$-monobromnaphthalene with plates of spar placed at the proper angles. This system transmits almost completely and without displacement the ordinary ray and totally reflects the extraordinary one. In cutting the spar, two directions in the crystal arestried. In the first system the longest axis of the plate lies in a principal plane through the optic axis, making an angle of $70^{\circ}$ with it. In the other the faces are principal planes through the optic axis, which is perpendicular to the longest edge of the plate. The first plate is about $2 \mathrm{~mm}$. thick, the second or sensitive strip only o. I $5 \mathrm{~mm}$.; the angle of each is $70^{\circ}$. He uses a special system of mirrors and prisms for obtaining a uniform illumination of the fields. A series of settings for the $C, D$, and $E$ lines is given, the single values deviating from the mean by from $0.004^{\circ}$ to about $0.005^{\circ}$.

BENTON DALES. 
Methods for the Investigation of Canceling Inks and Other Stamping Inks. By E. E. EwelL. U.S. Dept. Agr., Bureau of Chem. Circ. No. I2. 8 pp.- - Methods devised for the purpose of ascertaining the suitability of canceling inks for the use of the Post-Office Department, where a rapidly drying ink and one that is relatively indelible as compared with the ink used for printing the postage stamps is required.

H. W. LAWSON.

Determination of Sulphur in Steel. By B. F. WESTON. Iron Age, January i 5, 1903. - The evolution method gives results 0.005 to 0.025 per cent. low, in pig and cast iron. G. T. Dongherty has advocated annealing the drillings for fifteen minutes. The author has applied this annealing also to steel drillings of basic open-hearth steel. Results with I 2 samples showed a gain of 0.0005 to 0.004 per cent. sulphur by the evolution method, when the samples had been annealed fifteen minutes over a blastlamp in a covered porcelain crucible. The average gain was 0.003 per cent.

J. W. RICHARDS.

\section{METALLURGICAL CHEMISTRY AND ASSAYING.}

The Production of Minerals and Metals in the United States during 1902. By J. Strtthers. Eng. Min. J., January 3, I902. - With its accustomed enterprise, this journal prints on the third day of this year the approximate statistics of the last year. of the metallic ores, compounds, and metals produced, the following are the more important, the weights being in metric tons, followed by the total value at the place of production: Bauxite, 26,213 tons, $\$ 109,046$; carborundum, 1,724 tons, $\$ 342,058$; iron ore, $35,37 \mathrm{I}, 024$ tons, $\$ 57,443,100$; aluminum, 3,3 I I tons, $\$ 2$, 284,590 ; antimony in hard lead, 2,283 tons, $\$ 351,2 \mathrm{I} 7$; copper, 303,844 tons, $\$ 78,630,453$; gold, I 3 I. 968 tons, $\$ 87,7$ IO, I 89 ; pigiron, $18,024,423$ tons, $\$ 310,460,045$; lead, 242,690 tons, $\$ 21,770$, 534 ; mercury, I, I IO tons, $\$ \mathrm{I}, 488,22 \mathrm{I}$; silver, $2,09 \mathrm{I}, 567$ tons, $\$ 35,067,275 ;$ zinc, 143,742 tons, $\$ 14,380,650$. Some other important items were: Barytes, 45,359 tons, \$I 62,5CO; cement, 3, 904,334 tons, $\$ 29,195,748$; anthracite coal, $40,888,748$ tons, $\$ 82$, 93 I, 867 ; bituminous coal, 225 , I 89,9 I 2 tons, $\$ 295,389,950$; coke, $21,750,399$ tons, $\$ 61,118,621$; copper sulphate, 21,827 tons, $\$ 2$, 045, I 25 ; white-lead, I05,587 tons, $\$ 12,215,025$; red-lead, I 2,546 tons, $\$ \mathrm{I}, 437,054$; limestone used as flux, $9,695,763$ tons, $\$ 5,235$, 7 I 2 ; litharge, 9,858 tons, $\$ 1,057,696$; crude petroleum, Io, 583 , 843 tons, $\$ 65,761,604$; phosphate rock, I, 606, 293 tons, $\$ 5,338$, 065 ; pyrites, 308,606 tons, $\$$ I, I 94,064 ; salt, $2,889,353$ tons, $\$ 8$, $747,76 \mathrm{I}$; soda, 528,000 tons, $\$ 9,477,600$; zinc-white, 43,383 tons, $\$ 3,648,740$. The total value of non-metallic products was $\$ 886$, 694,362 ; of metallic products, $\$ 569$, 149,785 ; grand total, deducting duplications, $\$ 1,360,344,147$. J. W. RICHARDS. 